\title{
Robert Rattray Tatlock, F.C.S.
}

Robert RatTray Tatlock was born in Glasgow on May i8, i837, and died at Helensburgh on December 22, 1934. He was the elder son of Robert Tatlock, a manufacturer, and on the maternal side he could trace his ancestors, who were engaged in commerce, back to the early seventeenth century.

After his education at school, Tatlock's ambition was to be an analytical chemist, and he studied chemistry under Dr Penny, in Anderson's College. He was appointed assistant to Dr Penny, a post which he held for about eight years, and during that period his most important undertaking was the analysis of over a hundred "productions" in the case of Dr Pritchard, who had poisoned his wife and mother-in-law with an antimony compound.

He was for a time manager of a department of the Kames Gunpowder Company, Kyles of Bute, and in 1867 he began his career as an analytical and consulting chemist in Glasgow. In his laboratory commercial analysis was carried out, and there was a class for students, one of whom was the late Sir William Ramsay. He continued in active work, in partnership, until 1917.

In 1867 he was elected Fellow of the Chemical Society, in 1870 Fellow of the Royal Society of Edinburgh, in 1877 Fellow of the Institute of Chemistry of Great Britain and Ireland, and from I 883 to I 890 he acted as Examiner in Chemistry in the University of Glasgow.

During his years of active service he contributed a number of papers to chemical journals on "The Estimation of Potassium," "Some Sources of Error in Volumetric Analysis," on tea, coffee, the estimation of small proportions of bromine and chlorine in iodine, etc.

He was appointed Public Analyst in Glasgow in 1877, and later Gas Examiner and Sewage Analyst, and he was an expert witness in many cases.

R. T. T. 